\title{
Research on the Impact of Environmental Regulations on the Carbon Emissions of Heavy Pollution Industries
}

\author{
Mei Shang ${ }^{1 \text { st }, \text { a }}$, Degui Chen ${ }^{* 2 n d, b}$ \\ ${ }^{l} \mathrm{Xi}$ 'an University of Science and Technology $\mathrm{Xi}$ 'an \\ ${ }^{2} \mathrm{Xi}$ 'an University of Science and Technology Xi' an
}

\begin{abstract}
Based on the panel data of 18 heavy polluting industries from 34 industrial industries in my country as samples, empirical analysis of the impact of environmental regulations, energy structure, enterprise scale, corporate competitiveness, and technological innovation on carbon emissions of heavy polluting industries. And by constructing a dynamic GMM model to analyze the lag effect of environmental regulations on carbon emissions. The results show that: environmental regulations have a significant negative effect on carbon emissions, and the previous environmental regulations have a restraining effect on carbon emissions in the current period; energy structure will increase carbon emissions; technological innovation, enterprise scale, corporate competitiveness, etc. affect carbon emissions Has a negatively significant effect.
\end{abstract}

\section{INTRODUCTION}

Since the reform and opening up, Chinese industry has created huge economic output and has become a very important part of supporting sustained economic growth. However, with the rapid expansion of industrial scale, excessive energy consumption has led to the increasingly prominent phenomenon of carbon emissions, which has aroused widespread attention from domestic and foreign researchers on the low-carbon development of the industry: researchers are both concerned about global warming caused by carbon emissions. And worry about the adverse effects of carbon emission reduction on the economy. According to data from the US Carbon Dioxide Information Analysis Center, China's total carbon emissions surpassed the United States to become the world's largest carbon emitter in 2006, and reducing carbon emissions has far-reaching significance for a carbon emitting country like China.

\section{EMPIRICAL ANALYSIS}

\subsection{Independent variable: Strength of environmental regulations (ER)}

This article takes the intensity of environmental regulation as an explanatory variable. Because environmental regulations are social regulations, and accurate and intuitive quantitative data are difficult to obtain,scholars basically use alternative indicators. This article believes that it is more appropriate to use the operating cost of pollution control facilities as an alternative indicator of environmental regulation.

\subsection{Dependent variable: carbon emissions (EC)}

This paper selects the total energy consumption by industry to calculate the carbon emissions of each industry. It is calculated by the Kaya carbon emission identity method and the carbon chemical combustion formula method. The arithmetic average of the carbon emission coefficients of 2.277 and 2.72 per ton of standard coal is 2.499 , As the carbon emission factor per ton of standard coal.

\subsection{Control variables}

Taking into account the differences in technological innovation of different industry scales, as well as the competitiveness of different industries, different energy consumption intensity and energy consumption will have an impact on industrial carbon emissions, so this article selects technological innovation (TECH), enterprise scale (CSIZE), and R\&D Input, number of patent applications (TECH), total industry assets (TIA), industry profit margin (IP); energy consumption structure (RENE), energy consumption intensity (ECI); industry competitiveness (IC) as control variables.

\footnotetext{
a1257909297@qq.com $\quad{ }^{\mathrm{b}}{ }^{*}$ Corresponding author: deguich@163.com
} 
TABLE I. TABLE 2.1 VARIABLE DESCRIPTIVE STATISTICS

\begin{tabular}{|l|l|l|l|}
\hline Variable name & Mean & Targeting & Maximum value \\
\hline Carbon emissions (EC) & 9.603 & 1.302 & 12.060 \\
\hline Environmental Regulation (ER) & 2.974 & 3.188 & 17.820 \\
\hline Technological innovation (TECH) & 7.958 & 1.485 & 10.460 \\
\hline Industrial competitiveness (IC) & 1.055 & 0.171 & 1.940 \\
\hline Expenditure on scientific research (R\&D) & 14.000 & 1.682 & 21.420 \\
\hline Industry size (ISIZE) & 18.969 & 0.996 & 20.590 \\
\hline Enterprise size (CSIZE) & 10.423 & 1.286 & 14.420 \\
\hline Energy consumption structure (RENE) & 70.236 & 3.778 & 75.000 \\
\hline Economic level (TIA) & 18.868 & 1.021 & 21.020 \\
\hline Energy consumption intensity (ECI) & 0.639 & 0.537 & 3.990 \\
\hline Industry margins (IP) & 0.094 & 0.147 & 1.770 \\
\hline
\end{tabular}

\section{EMPIRICAL TEST AND RESULT ANALYSIS}

\subsection{Model construction}

According to Wang Rong [1]'s research results, the effect of environmental regulation has a negative and significant impact on the current carbon emission level. Therefore, this article attempts to add the first-order lag term of the environmental regulation level to the static environmental regulation model to form a dynamic panel data model. At the same time, it also achieves the purpose of testing the impact of past environmental regulation on current carbon emissions. Therefore, this paper constructs a GMM dynamic panel data model. In order to compare with it, this paper carried out the least square method (OLS) and fixed effects (FE) regression model on the static model of environmental regulation.

From the analysis of the system GMM estimation results, the regression coefficient of ER is -428.34 , which is much smaller than the fixed-effects model coefficient value -768.2352 , and is significant at the $1 \%$ level, indicating that the environmental regulations of the previous period significantly positively affected the current level, which Lu Zhengnan [2] reached the same conclusion. On the one hand, it shows that environmental regulation has "rigid" characteristics; on the other hand, it shows that environmental regulation means power, and the size of the power in the early stage will have a huge negative impact on carbon emissions. In addition, the combination of Sargan and the P value of the first-order $\mathrm{AR}(1)$ and $\mathrm{AR}(2)$ correlation coefficients is sufficient to show that it is reasonable to construct a dynamic panel data model of environmental regulation for regression.

Judging from the regression results of other control variables, the size of companies in the same industry (CSIZE) negatively affects the carbon emissions of heavily polluting industries, which is consistent with the conclusion of Sun Xuemin [3]. In the context of the continuous strengthening of environmental governance by the Chinese government, Large industrial companies are more inclined to adopt environmental protection technologies and measures to adapt to the current situation, while small companies must follow large companies to strengthen their environmental protection technology level to avoid being eliminated. This shows the importance of corporate scale for environmental pollution control. The regression coefficient of the total industry assets (TIA) in the model is positive, which means that the total assets of the industry are about more. The higher the amount of industrial production in the heavily polluting industries, the greater the energy consumption, and the more carbon emissions, which is consistent with Chen Guanxue [4 ] Consistent with the conclusions, he believes that the increase in GDP needs to be completed through industrial production, and these 
operations will inevitably use energy, thereby increasing carbon emissions; industrial competitiveness (IC) upgrades will reduce carbon emissions in heavily polluting industries It plays a significant role, indicating that the upgrading of industrial competitiveness can reduce carbon emissions, which is consistent with the conclusion of Zhang Jun [5]. From the OLS model, it can be seen that for every unit increase in competitiveness, carbon emissions can be reduced by 1.2072 units. Industrial competitiveness directly reflects the economic benefits of the industry. Through the upgrading of industrial competitiveness, enterprises have the ability to carry out low-carbon technological innovation, improve the efficiency of low-carbon technology, and encourage enterprises to focus on the use of advanced production factors such as knowledge, technology, and systems to develop the economy and reduce traditional Energy usage, thereby achieving carbon reduction. Energy consumption intensity (ECI) and energy consumption structure (RENE) have a positive and significant impact on the carbon emissions of heavily polluting industries, indicating that high energy consumption and high pollution are still the main factors for carbon emission reduction. Improve energy efficiency and reduce energy consumption

TABLE II. MODEL ESTIMATION RESULTS OF THE IMPACT OF ENVIRONMENTAL REGULATIONS ON THE CARBON EMISSIONS OF HEAVILY POLLUTING INDUSTRIES

\begin{tabular}{|c|c|c|c|c|c|c|}
\hline \multicolumn{7}{|c|}{ POLLUTING INDUSTRIES } \\
\hline \multicolumn{3}{|c|}{ Solution variable } & \multicolumn{2}{|c|}{ OLS } & \multicolumn{2}{|l|}{$\mathrm{FE}$} \\
\hline & coefficient & $\mathrm{t}$ & coefficient & $\mathrm{t}$ & coefficient & $\mathrm{t}$ \\
\hline constant & $0.5351 * * *$ & 9.3321 & 14. $1624 * * *$ & -9.6187 & 3156.3600 & 0.2680 \\
\hline ER & $428.3400 * * *$ & -50.3690 & $-0.02889 * *$ & -2.3330 & $-768.2352 * *$ & -2.0866 \\
\hline LnCSIZE & $-0.0096^{*}$ & 1.5253 & -0.0022 & 0.0563 & 0.0015 & 1.0199 \\
\hline LnTIA & $0.0593 * * *$ & 12. 4808 & 1. $0937 * * *$ & 17. 0037 & $0.0001 * * *$ & 9.4035 \\
\hline IC & 0.1897 & 1. 2363 & 1. $2072 * * *$ & 4. 3595 & 0.0776 & -0.4778 \\
\hline ECI & $0.0210 * * *$ & 2. 3701 & $0.9896^{* * *}$ & 14.2773 & $0.0673 * *$ & 2.212696 \\
\hline TECH & $-0.0368 * * *$ & -2.5852 & $0.0645^{*}$ & 1.6506 & $-0.6477 * * *$ & -3.4176 \\
\hline RENE & $0.0074 * *$ & 2.2547 & $0.0612 * * *$ & 4. 3164 & $294.6517^{*}$ & 1. 8724 \\
\hline IP & $0.0658^{*}$ & 1. 6108 & 0.1939 & 0.8076 & 0.0812 & 0.9430 \\
\hline Lnd & Yes & Yes & Yes & Yes & Yes & Yes \\
\hline year & Yes & Yes & Yes & Yes & Yes & Yes \\
\hline
\end{tabular}

intensity, Controlling the total energy consumption and reducing the proportion of coal use play an important role in promoting carbon emission reduction. Technological innovation has a significant negative effect on the carbon emissions of heavy-polluting industries. Analysis is made from two aspects. First, technological innovation is conducive to improving energy efficiency. After the introduction of carbon emission reduction policies, the three high industries such as cement, steel and electricity will reduce emissions. The pressure soared, and the elimination of high-energy-consuming and backward-looking enterprises and production processes has reduced the total energy consumption per unit of GDP; secondly, technological innovation promotes the use of new clean energy by enterprises, reducing corporate costs while reducing traditional energy consumption; The profit rate of the industry has a significant positive effect on the carbon emissions of the heavily polluting industries, indicating that companies will produce a large number of profitable products in order to maximize profits, and thus use a large amount of fossil energy. It also reflects from the side that the company is profitable and has a relatively weak awareness of environmental protection. 


\begin{tabular}{|c|c|c|c|c|c|c|}
\hline R2 & 0.9235 & & 0.9069 & & 0.9872 & \\
\hline F & $232.3752^{* * *}$ & & $186.4653^{* * *}$ & & $575.8665^{* * *}$ & \\
\hline Sardan-p & 0.4646 & & & & & \\
\hline AR(1) -p & 0.0236 & & & & & \\
\hline AR(2) -p & 0.7084 & & & & & \\
\hline
\end{tabular}

\section{ConClusions AND RECOMMENDATIONS}

This paper takes China's heavy polluting industries as a research sample from 2008 to 2018 and uses the systematic GMM method to perform regression analysis on the dynamic panel data of environmental regulations and industrial carbon emissions. The study finds that environmental regulations and industrial carbon emissions are negatively correlated with each other. In other words, under the premise that environmental regulations and industrial carbon emissions are closely linked, environmental regulations have a significant negative impact on industrial carbon emissions. This conclusion means that my country's environmental regulatory policies are reasonable. Therefore, my country's industrial sector should further improve the environmental regulations and policies issued by the state, and improve the level of technological innovation to reduce industrial carbon emissions.

\section{REFERENCES}

1. Wang Rong, Wang Ying. Research on the impact of FDI based on system GMM on carbon emissions in eastern, central and western my country[J]. Ecological Economy, 2018, 34(10): 24-28+34.

2. Lu Zhengnan, Feng Yang. The impact of environmental regulations on carbon emission performance from the perspective of technological progress $[\mathrm{J}]$. Science and Technology Management Research, 2016, 36(17): 229-234.

3. Sun Xuemin, Wang Jie. The impact of environmental regulations on the scale distribution of Chinese enterprises[J]. China Industrial Economics, 2014(12): 44-56.

4. Chen Guanxue, Yang Xuan. Research on the Impact of Energy Price Reform on Carbon Emission Reduction-An Empirical Analysis Based on Electricity Price and Carbon Emission Intensity[J]. Price Theory and Practice, 2019(04): 50-53.

5. Zhang Jun, Lin Qing, Wang Jiangquan. Research on the impact of industrial competitiveness upgrading on carbon productivity[J]. Journal of University of Electronic Science and Technology of China (Social Science Edition), 2019, 21(01): 94-103. 